\title{
Knowledge Asymmetries Between Research and Practice: A Social Systems Approach to Implementation Barriers in Organic Arable Farming
}

\author{
Egon Noe,* Hugo F. Alrøe, Martin H. Thorsøe, \\ Jørgen Eivind Olesen, Peter Sørensen, Bo Melander \\ and Erik Fog
}

\begin{abstract}
This article discusses the problem of implementing scientific knowledge in practice. The discussion is based on a case study of barriers to implementing research-based principles of sustainable organic arable farming. The current literature tends to see this problem either as a dissemination issue (the linear approach) or as a failure of science to address real-world problems (the co-constructive approach). We argue that Luhmann's theory of social systems offers a way to understand the shortcomings of existing approaches and enables us to identify knowledge gaps that have often been overlooked so far. This theoretical claim is substantiated by an empirical analysis based on Io in-depth interviews with owners of organic arable farms. The farmers were interviewed about barriers to the implementation of research-based knowledge in practice. The analysis points to the operational closure and the observational blindness of both research systems and farming systems as the keys to understanding knowledge gaps and suggests new ways of dealing with the problems of implementing research knowledge in practice.
\end{abstract}

\section{Introduction}

T he transfer of knowledge from research to practice is a perennial problem 1 of a wide range of fields including business (Levin 2000; Jasimuddin and Zhang 2009), public administration (Ospina and Dodge 2005), health (Jacobson et al. 2005), education (Newton and Sackney 2005), environmental studies (Hojem 20I2) and, not least, sustainable food production and rural development (Leeuwis 2004; Bruckmeier and Tovey 2008). Even when researchers believe they have found 
scientifically sound solutions to problems faced in the field, these solutions are often not put into practice. This is known as the implementation pro blem or the knowledge gap between research and practice (McCown 2002; Rossi et al. 2014).

The HighCrop project ${ }^{\mathrm{T}}$ reflects exactly this situation. Researchers have produced a substantial body of knowledge on organic cropping systems and a range of practical principles, but even though farmers know of the research-based principles thus derived, they have not been widely implemented in practice.

Organic arable farms in Denmark are strongly dependent on the import of manure from conventionally managed farms, and they are allowed to import up to $70 \mathrm{~kg}$ of nitrogen per hectare. For various reasons, however, there is an ongoing discussion on the possible phasing out of the use of conventional manure on organic farms. From a scientific point of view, this should motivate organic arable farmers to search for new solutions to their nutrient supply problems. Research in organic cropping systems has shown that there is a potential for increasing the robustness and level of productivity of organic arable systems and make them less dependent on input of nutrients from outside the organic farming system by means of a combination of crop rotation, optimised nutrient management and recycling, and weed control (Askegaard et al. 2008).

In the HighCrop project the main aims have been to collect and combine existing scientific knowledge on strategies for robust and resilient organic plant production and to translate this knowledge into practical principles. Many of these principles have existed for a while and are well known to farmers, but have yet to be implemented. This makes the HighCrop project a good case for exploring the questions of why scientific knowledge may not be implemented in practice, what the barriers to implementation may be, and how this knowledge gap between research results and farming practice can be understood and dealt with.

Based on the outcomes of the HighCrop project, this article aims at exploring the barriers to implementing research findings in practice. To do so, we apply a social systems approach as our analytical framework. We first argue for the choice of this analytical framework and give a short introduction to the social systems approach. Next, we describe the results of the analysis, which is based on Io interviews with owners of organic arable farms. Finally, we discuss the unique insights provided by the social systems approach.

\section{Approaches to the implementation problem and knowledge gaps}

In the literature of agronomic research and extension there are two primary ways to understand and deal with implementation problems and knowledge gaps: a linear model of dissemination and a co-constructive learning approach (Leeuwis and Aarts 20II; Klerkx etal. 20I2). Here, we provide a short introduction to different approaches in these two ways of addressing the problem and argue why we see the need to introduce a third way, the social systems approach.

The linear model sees knowledge as a product of science that has to be transferred from an expert to the potential user (Leeuwis 2004). It is a very widespread model that, among other outcomes, has resulted in the green revolution (Kloppenburg I99I; 
Norgaard I994; Warner 2008) and the development of the national extension programmes in many European countries. The linear model is especially useful in relation to specific and limited problems in specialised production systems like those producing piglets and broilers.

The linear model is, however, highly contested due to its limitations in describing and explaining more complex systems and problems such as the sustainable development of organic farming systems (Röling and Wagemakers I998; Morgan 20II), integrated plant production (Lamine 20II), and sustainable rural development (Bruckmeier and Tovey 2008; Tovey 2008; Knickel et al. 2009). Generally, there are three broad responses to this critique.

The first response we label the IT solution, by which problems of knowledge dissemination and knowledge gaps are met with technical solutions like decision support tools (McCown 2002; Jørgensen et al. 2008). A common feature of these IT solutions is that the users do not need to understand the knowledge involved in the computations; they only need to be able to apply the technology, for example, to supply the model with contextual information. However, for this solution to work, farmers and other users must perceive that it is necessary to use these tools, which is often not the case (Langvad and Noe 2006; Jørgensen et al. 2008).

The second response we label the diffusion model solution. It rests on the assumption that scientific knowledge is not directly applicable in practice and must be translated into practical principles before application can take place. According to the diffusion model, translation is best undertaken by a vanguard of the most innovative farmers whose example will then be followed by other farmers (see, for example, Ruttan I996; Padel 200I). This solution may work, but it presumes that other farmers are willing to follow the developments advanced by the 'innovative farmers', an issue which is the object of some discussion (van der Ploeg and Long I994).

The third response is to move research closer to practice, and thereby produce knowledge that is more readily applicable. Examples of this are on-farm research (Hildebrand I996; Collinson 2000), and systems research where one or more types of cropping systems are simulated on research stations (Olesen et al. 2000). This approach may be well suited for studying complex biological mechanisms, but it has also been highly contested because of the dissimilarity between research stations and commercial farms. In practice, farmers will dynamically change their responses to the changing conditions in their environment and as an outcome of the internal learning process of the farming system. The HighCrop project builds on findings and results from such systems research.

So far, the main critique of the linear model has come from the co-constructive approaches, in which the common ground is that they see knowledge as situated in context (Leeuwis 2004; Knickel et al. 2009). Generally speaking, the co-constructive approaches deal with knowledge gaps by surrendering the distinction between expert and layman, and seeing all stakeholders as experts on their own systems. Following the co-constructive approach, both scientists and farmers are considered to be experts in their own domain, and scientific knowledge is not considered as a more valuable or privileged form of knowledge and often fails to address real-world problems. Co-constructive approaches seem to work well for dealing with some complex problems like the reduction of antibiotic use in organic dairy farming (Vaarst et al. 2007). 
They are also widely developed and tested as multi-stakeholder involvement approaches in, for example, watershed management (Noe and Halberg 2002; Madsen and Noe 20I2) and rural development. It has, however, been criticised from a Foucauldian position for hiding power relations in the paradox of participation (Quaghebeur et al. 2004). Some realists criticise the co-constructive approach for downplaying what these realists see as the necessarily privileged position of scientific knowledge, instead of developing new ways of collaborating between practice and science (Koutsouris 20I2). So from our point of view, the co-constructive approaches do not provide an adequate answer to the question of how to deal with the gap between practical and scientific knowledge in dealing with a complex problematic situation.

Given the limitations of the two existing approaches as applied either individually or in combination, we suggest that there is a need for a third approach, based on social systems theory. As we argue below, such a model gives us the ability to overcome the analytical issues discussed above as well as those inherent to all actor-based models. This allows us to offer a more comprehensive explanation of the origins of the knowledge gap and to point to possible solutions.

\section{Theory: the social systems approach}

In this section we introduce and explain some of the key notions of the social systems theory that underpins the argumentation in this article. First of all, we describe how social systems theory considers farms to be self-organising autopoietic systems that operate by creating their own meaning and logic of production. Then we elucidate how social systems theory conceptualises knowledge, and how it sees the difference between scientific and practical perspectives as the source of knowledge asymmetries.

According to Niklas Luhmann (I995), social systems are characterised by being autopoietic and operationally closed, that is, they are self-referential and produce their own input for operation. Importantly, social systems are communicative systems that operate by making sense of the world through the selection between different pieces of information about their environments.

Operational closure means that the system relies entirely on internal operations; its operations always take place within the system itself. Another characteristic of an autopoietic system is that it operates only according to an internal systemic rationality or logical schema: 'a system's rationality cannot be clarified by referring to a superordinate, encompassing system’ (Luhmann i995, p. 474).

Complexity and contingency are two other central notions of social systems theory. The environment of a system is always more complex than the system itself (Luhmann I995, p. I82; Alrøe and Noe 2012). This means that the environment offers a surplus of possibilities, but it also raises the question of how a system can deal with a more complex environment, or reduce complexity, since it does not have the requisite variety to create a correspondence with every aspect of the environment. Every system is, so to speak, in a deficit of complexity compared to its environment. In communication every utterance offers a surplus of meaning, so further communication has to build on a selection between different meanings, leaving other possible selections out. The necessity of this selection is labelled contingency: 
Meaning is a representation of complexity. Meaning is not an image or a model of complexity used by a conscious or a social system, but simply a new and powerful form of coping with complexity under the unavoidable condition of enforced selectivity. (Luhmann I990, p. 84)

\section{Farms as autopoietic organisation systems}

The social systems approach to agricultural practice sees a farm as an autopoietic organisation system that can be observed as a continuous process of decision making, which forms a more or less coherent strategy (Noe and Alrøe 2003, 2006, 2012). An organisation system creates itself by closure, that is, through a continuous process of negotiations and decisions on what possibilities are included in the system and what are excluded (Noe and Alrøe 2006). These selections are contingent in the sense that, on the one hand, the organisation system is forced to decide and, on the other hand, it could have made other choices. An organisation system is thus forced to decide on a path of development that is not determined by the environment of the system, but rather by the contingent decisions made by the system itself.

The understanding of a farming system as being autopoietic entails some other features. Firstly, the continuous flow of decisions must be composed of systeminternal operations. It is only the organisation itself that can define what belongs to the organisation, and it has to produce and reproduce its own schema or logic which connects the flow of decisions. Such different logics of production can easily be observed empirically (Noe and Halberg 2002; Langvad and Noe 2006), and detailed studies have shown that there are several viable development strategies for otherwise similar farms (van der Ploeg and Long I994).

An autopoietic understanding of a system also entails a focus on meaning. Underlying the operating logic of the system is meaning, understood in terms of Viktor Frankl's notion of meaning as meaningfulness. Frankl claims that every human needs to find meaning that is self-transcendent and refers to something else outside the self, based on an existential will to meaning (Frankl I962). Translated into social systems theory, every organisation system must produce a self-transcendent meaning that refers to the system's environment. In an autopoietic system, this meaning is also produced as an internal operation. Instead of understanding farming systems as primarily goal-oriented systems, we see them as self-organising and autopoietic systems that are driven by the will to meaning - as what can be called logo-poietic systems (Noe and Alrøe 2005).

An example that illustrates this systems-theoretical understanding of a farming system is a dairy farm organised around high-yielding cows. The goal of such a farm would not simply be to achieve high yields: all the skills and craft required to achieve high yields and all the social relations, including events, awards and so on, involved would constitute the key meaning of the system. This means that every decision involving the cows in the farming system is made from this point of view; for example, what kind of milking equipment is used and how, which fodder items are included in the system, what kinds of observations are made by the system, what kind of labour is employed, and how these different elements interact in the system. The logic of production that binds these interpretations together could be something like: 'We need to be among the top ro yielding dairy farms to survive in the future, and therefore we 
need to focus on optimising conditions for all our animals'. Only by comparing with the systemic logics of other dairy farming systems will the contingency become clearly visible. Another farming system may, for example, be organised around rationalisation as the key meaning, grounding every decision on economic value, and having a logic of production that could be expressed as: 'We need to reduce the cost per kg of milk as much as possible, and therefore we need to rationalise our operations as much as possible, producing cheap fodder and using large-scale production to reduce the labour costs per cow'. Therefore, the key meaning is fundamental for the farming system understood as an autopoietic system, and changing the key meaning will call for a complete reorganisation of the system, including its internal logic.

This autopoietic understanding also means that it is the organisation system itself that observes and reacts to changes in its environment. For instance, if the price of milk decreases it is up to the dairy farming system as an organisation to recognise this as factor of change that demands a reaction. How it will react to changes is dependent on the logic of the system, for example, whether to increase milk yield or to expand herd size. No organisation system can be sensitive to all changes in its environment, so it is often observed that the systems are sensitive only to the changes that seem most important to pursuing their strategies whereby they reduce the complexity of their phenomenological world - the part of their environment they observe and react to (Alrøe and Noe 20I2).

\section{Perspectivism and knowledge asymmetries}

We also apply the social systems approach to the analysis of implementation problems and knowledge gaps, in which we consider knowledge in a perspectivist framework and see the existence of both scientific and practical perspectives as the source of knowledge asymmetries.

The perspectivist view of knowledge can be characterised in a few sentences. There is no perspective on the world that is external to all observers. All knowledge comes from a certain perspective. All learning happens in applying specific perspectives to the world, and these perspectives are themselves part of the world and can themselves be made objects of observation. A scientific perspective, such as a discipline, a school of thought or a specific research approach, is also an autopoietic system that is reproduced and refined through internal processes (Alrøe 2000; Alrøe and Noe 20I4). A specialised scientific perspective presupposes certain concepts, theories, classifications, instruments, problems, etc. (Alrøe and Noe 20II). This specialisation delimits and focuses the field of observation and makes the scientific perspective able to observe certain phenomena and aspects of its environment. At the same time the specialisation makes the perspective blind to other phenomena and aspects of its environment. Each perspective has its blind spots, which cannot be observed from that particular perspective, but which can be observed from other perspectives. The differentiation and specialisation of science enables science to make better, deeper and more robust observations, and at the same time deepens the gaps between scientific and practical knowledge as well as between different specialised scientific perspectives. In order to better handle these different kinds of 'knowledge gaps', we introduce the concept of knowledge asymmetries. 
Based on the idea of knowledge asymmetries, Alrøe and Noe (20II) have developed a typology of three problems of knowledge asymmetry: ordinary problems, paradoxes and dilemmas. Ordinary problems are the well-known problems of knowledge transfer between expert and layman, or between researcher, extension agent and farmer, as reviewed above in connection with the linear model, where the farmers must learn to catch up with the expert or where the expert must move into the farmer's field of practice.

Paradoxes are connected to the burgeoning number of scientific fields of expertise with different perspectives. The growth of knowledge in modern society necessarily leads to knowledge fragmentation due to the differentiation and specialisation of scientific disciplines. The paradox arises when a problem that calls for more knowledge cannot be solved by applying more knowledge to it due to the fragmentation and ensuing disagreements between different branches of scientific knowledge (Alrøe and Noe 20II). In a systems-theoretical understanding paradoxical knowledge asymmetries cannot be solved by way of the means and distinctions that constitute them; this will only reinforce the asymmetry. For example, we cannot solve the problem that the farmer has to deal with more and more forms of specialised scientific knowledge by adding on more knowledge that has to be dealt with. To resolve a paradox you need to transgress the framework in which the paradox exists, by involving new perspectives. The existing forms of interdisciplinary and transdisciplinary research are efforts to deal with the fragmentation of science, but they do not have the means to resolve paradoxical knowledge asymmetries, because they do not recognise the full impact of the choice of scientific perspective on the observations made through the perspective (Alrøe and Noe 20II, 20I4).

The third type of problems of knowledge asymmetry is the dilemma, in which the knowledge asymmetry is connected to a conflict due to an asymmetry in power, agendas or interests. These problems cannot be resolved only by means of knowledge transfer, since this may lead to increasing the conflict resulting from the dilemma. For example, if an environmental expert from the local authorities (that also inspect farms to ensure adherence to environmental regulations) tries to teach farmers about the environmental effects of their farming practices, this could result in increased tensions between authorities and farmers in relation to environmental regulations. The problem with such a dilemma is that the more experts try to push the farmers in the 'right' direction, the more they also emphasise the power involved in this relation, which can have the opposite effect. Such dilemmas are not simply solved by participatory approaches, because this does not transcend the power relations involved (Quaghebeur et al. 2004). We can find the same kind of dilemmas in the implementation of research knowledge, where the power involved is the power of having the right kind of knowledge, due to the commonly held idea that scientific knowledge is superior to practical knowledge.

\section{Materials and methods}

To explore the barriers to implementing principles of robust production systems, Io organic arable farms were visited for an interview. The cases were selected based on two criteria (Flyvbjerg 2006). Firstly, it was decided to focus on full-time, organic, 
Table 1: Brief general description of the variation of farming systems in the study

\begin{tabular}{|c|c|}
\hline Size & 80 to 800 ha \\
\hline Soil types & Variation from sandy to loamy and peat soils \\
\hline Crop production & $\begin{array}{l}\text { Primarily: spring oats, spring barley, peas, grass-clover, lucerne; some } \\
\text { farms with ryegrass for seed, field beans etc.; few fields with other crops. }\end{array}$ \\
\hline Animal production & $\begin{array}{l}\text { Two farms with minor production of beef cattle grazing on permanent } \\
\text { pastures; one with cooperation with a free-range piglet producer. Other } \\
\text { farmers have more or less extensive cooperation with animal } \\
\text { husbandry farms. }\end{array}$ \\
\hline
\end{tabular}

specialised arable farmers certified through the Danish governmental certification system, as the challenges and motivation for developing robust farming systems were expected to be strongest here. Secondly, the HighCrop project partners from the Danish Knowledge Centre for Agriculture were asked to suggest potential farmers, representing the variation among organic arable farms. They suggested i6 farmers, of whom io were selected to participate in the interviews (Table 1). Except for one farm all the organic farms were full-time farmers. Among them, the first farm to be certified as organic obtained its certification in 1982 , while the last one obtained it in 20I0. The farmers were all male, which reflects the overall picture in Denmark.

Two of the methodological choices made were unconventional, but in line with social systems theory. The first was that we asked the farmer to invite the primary crop production advisor to participate in the interview if the advisor had played an important role in the decision-making of the farming system. The purpose was to better observe the communication involved in the decision-making of the farming system in the interview; for example, what kind of arguments were employed and what logic these arguments were based on. We asked the farmer to make the decision because the role of the advisor must be a system-internal decision. As a result, advisors participated in cases 3, 4, 5, 6, 7 and 8 .

The second methodological choice was to have two researchers from the HighCrop project participate in the farm visits and interviews. This had a dual purpose: (I) to make the knowledge gap between research and practice as tangible and concrete as possible in the interview situation, with the researchers representing the scientific knowledge; and (2) to enable the researchers to observe the very different practices of the farming systems.

To investigate barriers to implementing the principles of robust organic arable systems, we needed to be very specific about what actions these principles recommend in practice. Therefore, researchers involved in the HighCrop project representing different research perspectives on organic farming were asked to prepare a list of basic principles on both weed control and nutrient management for robust organic arable farming and then to suggest potential actions derived from each principle (Table 2). To support focused communication about the barriers, the HighCrop project partner from the Knowledge Centre for Agriculture created a set of picture cards (see Table 3), illustrating each of the suggested actions (Fog 2013). 
Table 2: List of principles and actions for obtaining high-yielding and robust arable plant production systems, produced by the experts in nutrient management and weed control involved in the HighCrop project

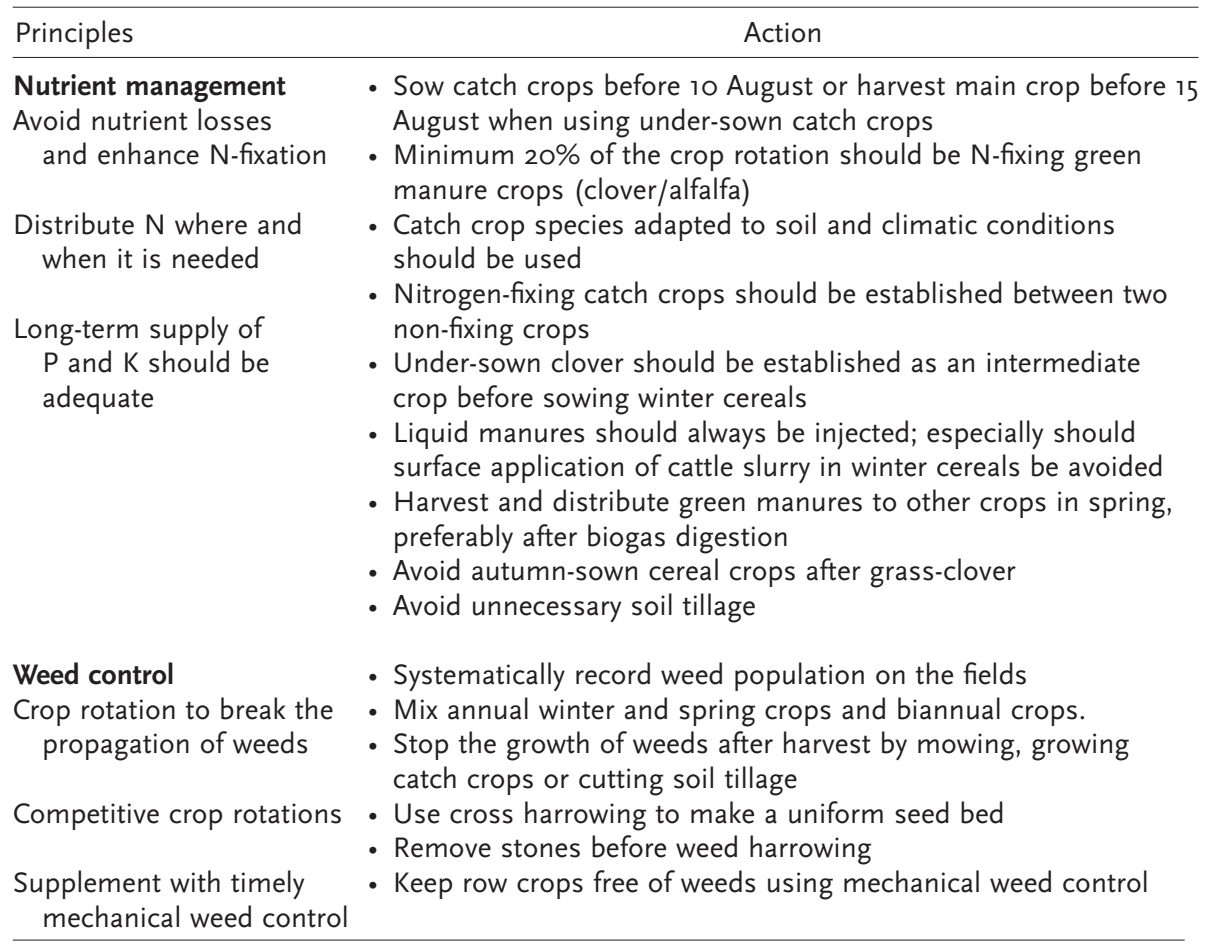

K: potassium, N: nitrogen, $\mathrm{P}$ : phosphorus

Our interview methodology takes as its point of departure a phenomenological hermeneutic approach (Kvale and Brinkmann 2009). However, given our systems theoretical foundation, our main interest is not to gain phenomenological insights into the motivation or behaviour of the farmers, but rather into the farms as organisation systems.

The visit to each farm started with a walk and talk around the farm to get a visual image of the farming system. The interview consisted of two parts. Part one explored the general management strategy of the farming system and part two explored the barriers to implementing the suggested actions for a more robust arable farming system. In this second part the farmer was asked to consider each of the suggested actions, and to sort the picture cards into three categories according to whether these actions were (I) already implemented, (2) realistic to implement, or (3) unrealistic or irrelevant to implement on the farm. To the extent that the farmers had asked for it, the two research experts elaborated on their explanation of the principles and actions. Each interview was tape-recorded and photographs were taken of the placement of the picture cards. 


\section{Results}

In the following we present the results of the interviews. The cases represent different meanings, values and farm development strategies. We first describe the logics of production found in the different cases, as they may help the reader to understand the specific agronomical, technical and economic barriers to implementing the suggested actions described in the following sections. We then describe how the barriers relate to the logics of production.

\section{Logics of production}

In Cases I, 9 and Io, the meaning and values are strongly linked to a logic of productivity and agronomical skills. These farmers are very dedicated plant producers, and high yields and field experimentation play an important role in the farming system. This rationale can be illustrated by cases I and Io, where winter cereals are grown after grass-clover to maximise cereal grain yield. They have a varied crop rotation and the crops are selected to fit the conditions of the individual field.

In Cases 3 and 7 the value and logic of production flexibility play a dominant role. Even though the two systems of Cases 3 and 7 are very different, they are both keen to try new things, new crops and new production strategies. As an example, Case 3 combines clover seed production with honey production in cooperation with a beekeeper. The farmer has invested in beehives and made an agreement with the beekeeper to take care of the bees while sharing the production of honey. Furthermore, the farmer owns a drainage company and has a sideline in importing agricultural machines. As he explains the situation, the sales volume and size of the business is large enough for him to be able to change his machinery and use advisors and employees when taking up new activities. The interviewee in Case 7 has tried many new special crops and seed crops. Lately, he has taken up small-scale organic chicken production. As he says, it is a very small investment, so he can easily stop this production if it becomes unprofitable.

In some of the other cases, it was the internal cohesion of the production system that characterised the values and logic of production. In Case 6, this logic emerged from the farming system cooperating with a production system of free-range pigs and working land composed of sandy soil. The production of crops was targeted at the production of fodder for the pigs. In Case 2, the production of plants was adjusted to the production of beef cattle, which meant that they could afford growing grass-clover for feeding purposes on 20 per cent of the farm area, and the beef cattle produced some solid manure to support a better distribution of nutrients in the crop rotation. In Case 8, a small plant production system, there were no animals but the internal cohesion was centred on the development and adjustment of five-field crop rotation.

In a single case (4), the overriding value and logic of production was the rationalisation of the operations of the farm. The farmland in Case 4 was dispersed over many fields over a large area up to $70 \mathrm{~km}$ away from the main farm buildings. This frames the choice of crops to reduce the number of operations per field. One of the main conditions is the availability of organic manure from animal productions closer to the 
fields. The logic of rationalisation also links a systematic approach to planning (optimising logistics) to the operations of the farm.

The different logics of production represented in these cases demonstrate that farming systems are continuously confronted with the need to make choices between different possible options for the development and reproduction of the system in which they are guided by an overall meaning, a logic of production and certain core values, all of which reduce the complexity of decision-making. As we shall see, this affects the nature of the barriers to the implementation of actions suggested by scientists.

\section{Barriers}

Only very few of the suggested actions were new to the farmers. Except for a single farmer, everyone had a well-rounded understanding of the principles of robust crop rotation and nutrient cycling. Nevertheless, none of the farmers interviewed actually applied all the actions or was willing to apply them (Table 3). This confirms empirically that it is a decisive challenge to bridge the knowledge gap between science and practice. It also demonstrates that there is a need for a more thorough investigation of what the real barriers are to implementing these principles, since they do not simply consist of a lack of knowledge. In the following, we analyse some of the main reasons that the farmers and their consultants gave for not implementing the suggested actions.

\section{Nutrients: no burning platform}

First it is worth mentioning that all farmers were able to import conventional manure up to the permitted limits of $70 \mathrm{~kg}$ nitrogen/ha, and some farmers had access to supplement their production even further by importing organic manure, allowing them to exceed the import limit of $70 \mathrm{~kg}$ nitrogen per year. This is clearly reflected in the barriers that farmers identify for those actions that target nutrient supply. Only three of the io farmers focused on the production of catch crops, that is, those crops that are able to take up nutrients from the soil in the autumn and store them organically for the next growing season, preventing the nutrients from being washed out by rain during the autumn season. Six farmers grew nitrogen-fixing green manure crops on at least 20 per cent of the farm area (Table 3). Only one had planted nitrogen-fixing catch crops between two non-fixing crops. When it comes to the injection of liquid manure, only four of the farmers consistently use this technology, and the reasons for not doing so varied. One farmer had his own slurry spreader which lacked injection equipment and he wanted to avoid the additional costs of acquiring such equipment. A couple of farmers used the soil conditions, a combination of clayey soil and steep slopes, as an argument for not injecting, stating that they were afraid of soil compaction and other damage to the soil. None of the farmers practised any form of storage or redistribution of green manure. The farmers saw no economic rationale in doing so for various reasons. Most of them already had access to sufficient quantities of manure to assure them the necessary flexibility for the timely application of manure to maintain yields. None of the farmers grew high-value crops that could pay for the extra costs. Many of the farmers had considered the idea 
Table 3 Possibilities for implementing the suggested actions for robust organic arable cropping systems, seen from the perspective of the farming systems

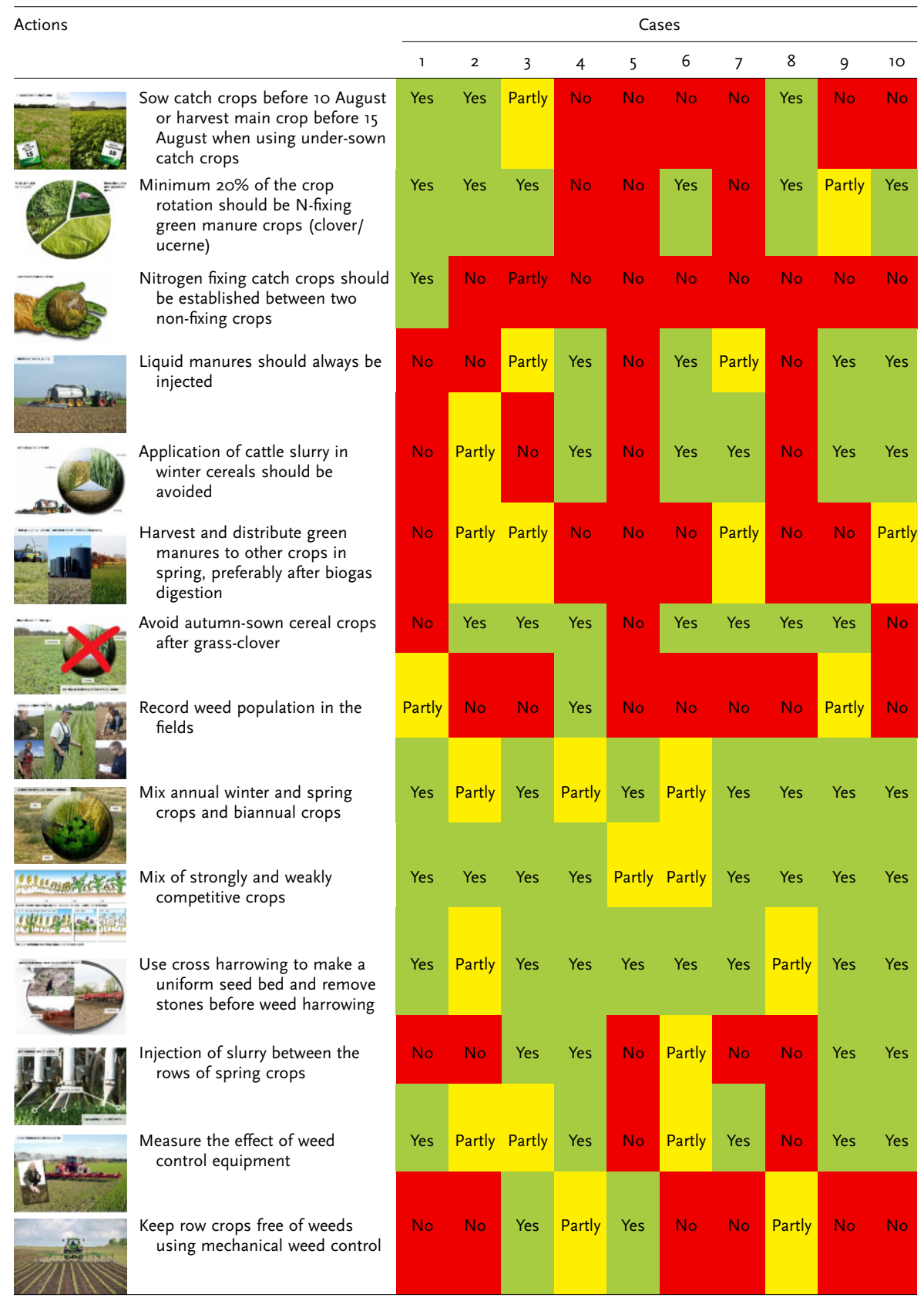

(C) 2015 The Authors. Sociologia Ruralis (C) 2015 European Society for Rural Sociology.

Sociologia Ruralis, 2015 
of biogas production, but none of them were willing to make any investments at the moment; they could not see any point in considering it before it had been proven profitable to produce biogas, and they were also reluctant to invest in it as long it was possible to obtain manure in other ways.

\section{Trade-off between weed control and nutrients}

One of the prevailing issues raised by farmers in the interviews was the trade-off between weed control and nutrient management. For the farmers, the issue of weed control in general plays a more important role in their practices than nutrient management. This being said, the farmers employed very different strategies to achieve a balance between weed control and nutrient management. One extreme was Case 5, who had only spring crops, no legume crops and no catch crops. His main concern was to practice mechanical weed control after harvest; and he practiced mechanical weed control in autumn as long as the weather allowed. The context was that he had recently sold his organic dairy cattle and now ran the farm as an arable farm, which means that the soil was still very fertile due to the previous dairy cattle system. In this case, the mechanical weed control concern overruled both the considerations for fixing nitrogen and for avoiding the loss of nutrients. This was linked both to the values of the farmer and, to a certain extent, to the lack of understanding of the basic principles of organic crop production systems of both the farmer and his advisor. At the other end of this spectrum was Case 8, who had a regular five-field crop rotation system designed as a trade-off between nutrient and weed control, including 20 per cent of the farm area with grass-clover for cutting and a window of time for mechanical weed control. Another purpose of this strategy was to keep the management of the system as simple as possible. In between these two positions we observed a range of different strategies. Only a few of the farmers gave priority to growing catch crops in the autumn. There were various reasons for that, expressed by sentiments such as: 'it is difficult to manage to sow in the harvesting period' and 'late harvesting due to late sowing because of cold soil limits the possibilities for growing catch crops'. When it comes to the scientifically proposed action of growing nitrogen-fixing catch crops, almost none of the farmers found this worth doing, mostly due to the cost of seed. Only one of the most dedicated arable farmers (Case I) included this in his strategy, but this was mainly due to the fact that there were already a lot of white clover seed in the soil, which naturally grew into a nitrogen-fixing crop after harvest.

\section{Systematic weed registrations and farmer decision-making}

One of the suggested main principles of weed control was a systematic registration of both annual and perennial weeds as part of a systematic weed management strategy. Surprisingly, only one of the farms studied systematically registered the weed population while the other farmers claimed that they knew their fields well enough to be able to do without systematic registration. This claim was held even by farmers running more than 350 ha of land (Cases I, 3, 4 and IO). When the topic was raised as an issue in the interviews with the farmers, only a few would consider putting more 
emphasis on systematic registration. One of the large-scale farmers mentioned, though, that he would consider keeping a large map in his office to be able to mark the more problematic species on his fields (Case 3). But he saw no reason to go into further detail or to apply geographic information system maps.

A key to understanding why farmers neither systematically register weeds nor wanted to do so is to look at how they make decisions in relation to their management.

One argument repeated by the farmers in many of the interviews is that they are personally involved in the field labour and that they know their fields. One farmer claimed that he always insists on driving the combined harvester as a way to keep in touch with his fields. This gives an idea about how farmers include knowledge about weeds in their strategy and decision-making. Concerning perennial weeds, none of the farmers used spot treatments on the fields. Instead, they treated the whole field; their rationale being that when they were driving they might as well treat the whole field at the same time.

This is also closely linked to the general weed control strategies of the farms. Here different strategies can be identified. Some of the farmers have chosen a mechanical approach to weed control, especially those of Cases 3 and 4 who had recently invested in row-based mechanical weed control supported by global positioning system technology. In Case 6, which had sandy soil, summer bare fallow was used as a window of opportunity to control weeds, and especially couch grass. Due to the sandy soil, the economic costs of keeping a short summer bare fallow are small compared to the gain in effective perennial weed control.

Other farmers focus more on crop rotation designs to prevent and cope with weeds and to avoid mechanical interventions as much as possible. In Cases I, 7 and 9, the farmers adjusted the crop rotation to the weed problem of the individual field, whereas in Case 2 and 8 they simply selected a very robust and competitive crop rotation, which included 20 per cent of grass clover, rye and oats.

The monitoring of weeds done by farmers is informed by their management and decision-making strategies. A more systematic registration of weeds would not make sense to them, given their present strategies, as it would require a change of these same weed management strategies (Langvad and Noe 2006).

This is not the same as concluding that the weed management strategies cannot be improved from an agronomic point of view, but the farmers interviewed certainly did not prioritise such improvements. One of our general observations made in the interviews is that there are other concerns that seem more important to the farmers than weed control; and most farmers are of the opinion that, one way or another, they will be able to handle weed problems when and where they may occur. This suggests an analysis of what, then, the actual guiding principles of these organic arable systems are.

\section{Concern for production, harvesting and storage capacity}

Many of the barriers addressed above can be seen in the context of major strategic decisions made in the development of the production system which limit the possible set of future choices made by the system. All farmers came back to the issue of choices already made. In Case I it was the handling and storage capacity of the harvest that constituted one of the decisive factors for the crop rotation and plant 
production strategy. Four silos were built on the farm, which meant that it could store, and hence, harvest, four major crops. The logistics of handling harvesting capacity is another major concern for several cases, especially Case 4, in which the concern for logistics played an even greater role due to the dispersed farmland located up to $70 \mathrm{~km}$ away from the main buildings. Investment in other kinds of equipment can also frame the organic arable cropping systems, like the investment in advanced row weeding systems in Case 2, which obviously calls for crops suitable for sowing in rows.

Cooperating with other farming systems can also play an important role in framing the cropping systems. As mentioned in the methods section, all the cases were intentionally selected as arable organic farming systems, and in a legal sense they were arable, except for three farmers who had minor productions of beef or chicken. But it seemed that almost every farm had a long-term arrangement with an organic animal production enterprise, both to import organic manure and to produce and sell grass-clover for silage.

Arguably, all these choices could have been made differently, but once they had been made, they framed and conditioned any decision following them, which is what we term the paths of development of the farming systems. The economic performance of the farming systems is very strongly correlated with their ability to make decisions that are in line with previous choices made, as it impacts on their utilisation of their storage capacity, the availability of labour, the cooperation with other farming systems, and so on. Consequentially, actions that seem easy to implement from a scientific point of view can be immensely difficult or meaningless from the perspective of the farming system, because they conflict with the path of development or the logic of production of the system.

\section{Robust crop rotation, conditioned by marketing}

The internal coherence of the path of development of the farming system plays an important role for decision-making. All the farmers interviewed claimed that they strove for an organically sound crop rotation that includes competitive species and targets the biological needs of the most problematic weeds. But when entering into a deeper discussion with the farmers, it appears that other concerns get higher priority. For example, in Case 6, in which the farming system cooperates with a free-range organic pig production, rye would have been an obvious choice for competing with weeds on the sandy soils, but the farmer did not consider rye suitable for feeding the free-range pigs and so abstained from producing it.

Short-term market expectations constitute another important factor in the choice of crops. In those cases where the farm had no contractually based cooperation with an animal production system, the economy of the farm depends on market prices and the marketing opportunities for the crops. For example, in Case 4 oats became the major crop due to beneficial market access for that crop and the market concern overruled concerns about nutrient cycling and effects on weeds and diseases from improved crop sequences. However, the import of manure made such a strategy possible anyway. In summary, many of the farms did not employ fixed crop rotation, but strove to include as many profitable crops as possible in order to sustain 
the system. From a long-term agronomical perspective, this may not be perceived as the optimal choice, whereas it does from the perspective of a farmer, who is used to dealing with volatile conditions such as fluctuating market prices, shifting weather, variations in the incidence of plant diseases, and so on.

\section{Barriers, systems, logic and meaning}

So far, we have analysed the barriers to implementing the principles of robust organic arable production systems, agronomical, technical and economical, and how different paths of development form these barriers. A fundamental way of understanding these different strategies and paths of development is to look into the meanings that guide the different farming systems and the associated values and logics of production, which we presented at the beginning of the results section. By observing the values and logics of production of the farming systems, a pattern is traceable in the way different farmers see the possibilities and barriers to implementing the suggested actions.

Economic concerns played an important role for all the farming systems. But how the economic options are calculated and prioritised varies greatly from farm to farm. One of the farmers, whose farm had an internal cohesion strategy, preferred to use the slurry spreading equipment owned by the farm, using trail hoses. His rationale was that it would be far too costly for him to contract for direct injection, also because he grows crops where trail hoses may be used. For another farmer these extra costs are not a problem because they have the necessary injection equipment themselves. One of the dedicated plant producers wanted to protect soil fertility on a farm with steep fields and clay soil. The argument used for not harvesting and redistributing green manure varies depending on the values and logic of the farming system. For the flexible farmers, building biogas reactors is not an attractive economic option at the moment, but if its profitability increases, they will consider the possibility and the associated marketing opportunities. The farmers who orient themselves towards production have little faith in the production of biogas at the moment, either, but they indicated that they would reconsider their position if the legislation on the use of conventional manure were to change. The internalcohesion farmers have adjusted their production to the internal supply of nutrients. For the farm based on rationalisation, the dispersed fields and the crop rotation did not allow for a rational reallocation of green manure or biogas digestates.

\section{Discussion}

We initially highlighted three types of knowledge asymmetries as an analytical framework to better understand the knowledge gaps and the barriers to implementing research knowledge in practice. The following discussion is structured according to this typology of knowledge asymmetries.

\section{Ordinary problems of knowledge asymmetry}

The interviews with the farmers exemplified some ordinary problems of knowledge asymmetries, where the farmer lacks the knowledge necessary to improve his strategy 
and production. In a few cases it seems that the farmer lacked insight into farm nutrient house-holding. Some of the farmers asked for more detailed knowledge on growing nitrogen-fixing crops. The farmers were also interested in acquiring more knowledge about how to control problematic perennial weeds like coltsfoot, thistles and couch grass. This means that there is still a need for the extension of knowledge in its traditional form, although new tools could be used to improve the transfer of knowledge. These ordinary knowledge asymmetries, however, cannot explain all the barriers to implementing research-based principles and actions. Many farmers already knew of most of the principles but had not implemented them in practice, which may be explained by the presence of the two other types of knowledge asymmetries.

\section{Paradoxical asymmetries}

As described in the introduction, the production of more scientific knowledge from different disciplines also fosters additional knowledge asymmetries. Paradoxes arise when additional knowledge does not solve the farmer's problem since the new knowledge is in conflict with knowledge or advice from experts from other scientific disciplines or sub-disciplines.

The paradoxical knowledge asymmetries revealed in our study generally show up in form of internal conflicts in the system. This means that the knowledge produced from one perspective would conflict with knowledge produced from another perspective, with the result that there is no single optimal solution. An example is the trade-offs between nutrients household and weed control with regard to productivity: implementing the knowledge in terms of the principle of weed control can lead to increased loss of nutrients, and implementing principles of nutrient management can lead to increased weed problems. As an example, none of the farmers used nitrogen-fixing catch crops between two non-nitrogen-fixing crops, mainly based on the argument that they need the autumn period for mechanical weed control. But often the situation is considerably more complex as concerns of harvesting, storage capacity and marketing all need to be considered.

Thus, these paradoxical knowledge gaps only get bigger when more knowledge is produced and more perspectives are introduced. Many of the barriers to implementing the actions suggested can be traced back to such paradoxes.

There is a further aspect to understanding paradoxical knowledge gaps, which is linked to the contingency of the different paths of development and the related values and logics of production. This means that the paradoxes are specific to the path of development of each farm. So what may be a problem for one farm can be a solution for another. Since the contingent nature of a path of development is unavoidable, such a problem cannot be adequately understood simply in terms of a lack of rationality, but must be seen as a necessary precondition that science has to deal with. Science has to start with the everyday reality of the farmer and the organisation of each specific farming system and include its values and logics. There are different strategies for overcoming the problems of paradox, such as system research, in which field trials that simulate different crop rotation systems are held; on-farm research, which integrates field trials in existing farming systems and farm research, which observes and describes real farming systems. But they are all struggling to deal with the 
challenges connected to experimental crop rotation. Science may obtain stronger and deeper insights into general biological and biogeochemical mechanisms linked to crop rotation, nutrient management and weed management on specifically designed crop rotation systems, but these designed research systems will not resemble any of the dynamic crop rotation systems of the different farms. This may be a strong overall explanation of why the principles derived from research into cropping systems are not readily applicable in the real world of farming systems (Alrøe and Kristensen 2002). The existing co-constructive approaches do not solve this paradox. Firstly, because they produce knowledge specific to each system and knowledge from one system cannot simply be transferred to other systems. Secondly, because co-construction does not transgress the conditions of perspectival knowledge; co-construction will always be from a certain perspective, and is likely to contribute to the paradox of knowledge.

\section{Dilemmas}

This limitation leads us to the third type of knowledge asymmetry problems; the dilemma, where a knowledge asymmetry leads to a conflict due to an interconnected asymmetry in power relations (Quaghebeur et al. 2004; Mahon et al. 2010). In the present context, this could be the advisors with their own interests, that may or may not agree with the interests of the farming system. As a result the advisor may seek to advance the implementation of certain types of knowledge over others deemed to be less advantageous. The same may be true for researchers. For example, the goal of the HighCrop project to promote more robust systems is not necessarily high on the agenda of farmers, and the scientific knowledge dissemination activity is therefore likely to be affected by a clash of interests.

Science makes progress by making observations in a very specific, specified and well-documented manner, using the methods and instruments of the particular science in question to produce knowledge of certain aspects of the problem in question. In this way science is able to produce generalised knowledge in the sense that it is applicable and valid outside its original context, within the constraining conditions of the observational methods (Alrøe and Kristensen 2002). Though scientific knowledge is often considered non-contextual, it is more accurate to say that each scientific perspective operates within a delimited research world, which is the phenomenological world that the knowledge it produces originates from. When addressing any reasonably complex problem, it is impossible for this research world to be congruent with all the different practice contexts, in this case the different organic arable production systems. Therefore, the research system may inadvertently seek to advance its 'more valuable form of knowledge' without due concern for the practical context and the interests of the farming systems. This may produce a conflicting situation because it creates a defensive attitude among the farmers that, from the inside, seems necessary to defend the internal cohesion of the farming system.

To solve this problem, science needs to find a way to include the practical insights of the farming systems. But the dilemma is that science cannot at the same time be both superior and inferior to practical knowledge. Action research is not an answer either, because this is a way of circumventing the dilemma without really addressing the idea of the superiority of scientific knowledge. 


\section{Conclusions and perspectives}

In this article we have carried out a social systems-based analysis of the barriers to implementing research knowledge in practice, using the case of barriers to implementing research-based sustainable principles of organic farming originating in the HighCrop project.

Such barriers are generally understood to be problems of the dissemination of scientific knowledge or as knowledge gaps between science and practice. The present analysis shows that a social systems theory approach can offer new ways to understand this problematic compared to existing approaches.

In particular there are two issues that the established approaches are not suited to observe and address: closure and blindness. Closure is a fundamental aspect of social systems seen as autopoietic communicative systems. Such systems cannot be directly instructed, but instead determine themselves which parts of their environment they open up to in accordance with the key meaning they are organised around. Blindness is the other side of closure. Each social system has its own perspective which determines what it can see and what it cannot see. In other words, each social system has blind spots. This goes for the farming systems that we have studied as well as for the different scientific systems and extensions systems involved.

With the social systems approach we can observe two new kinds of knowledge gaps in addition to the ordinary knowledge gaps that the two previous approaches address: paradoxes and dilemmas.

An example of a paradoxical knowledge gap that we identified in the analysis is the paradox between the different research perspectives involved organic arable farming over weed control and nutrient management, respectively. Implementing researchbased knowledge on mechanical weed control in practice is likely to increase the loss of nutrients from the farming system, and implementing knowledge on nutrient recycling is likely to increase the problems of controlling weeds. More scientific knowledge on weed control and on nutrient management will only exacerbate this paradoxical problem. And as the ro cases in this study illustrate, there is no universally applicable trade-off or balance between these concerns since in each case the solutions available, as well as costs and benefits depend on the specific farming systems, but also on system-external issues such as fluctuating market prices, weather conditions and more.

A prime example of a dilemma which we identified in this analysis is that the different farming systems did not share the overall goal and understanding of robust organic farming that is closely linked to the scientific understanding behind the HighCrop project. The various farming systems were organised around key meanings and system logics that were different from those of the HighCrop project. The more the researchers tried to use their status as researchers to convince the farmers, the more the farmers would defend their position, and this only reconfirmed the dilemma. If the researchers instead try to approach the dilemma by accepting the key meanings and logics of the farming systems they also have to give up the idea of a robust system and take as their starting point the logics and problems as understood from the different farming systems' perspective. This will completely change the basis on which the research findings have been produced. 
Systems theory has its own blind spots, as do all analytical perspectives, but it offers the key understanding that only by continuously observing the blind spots of other systems can the paradoxes and dilemmas of implementing research findings in practice be overcome. This insight points towards the need for further research into multi-perspectivist approaches to understanding knowledge gaps.

\section{Notes}

* Corresponding author.

I Higher productivity in Danish organic arable farming (HighCrop), an organic Research, Development and Demonstration project financed by the Danish Ministry of Food, Agriculture and Fisheries (http://orgprints.org/I9608).

\section{References}

Alrøe, H.F. (2000) Science as systems learning: some reflections on the cognitive and communicational aspects of science. Cybernetics Q Human Knowing 7 (4) pp. 57-78

Alrøe, H.F. and E.S. Kristensen (2002) Towards a systemic research methodology in agriculture: rethinking the roles of values in science. Agriculture and Human Values I9 (I) pp. 3-23

Alrøe, H.F. and E. Noe (20II) The paradox of scientific expertise: a perspectivist approach to knowledge asymmetries. Fachsprache - International Journal of Specialized Communication $34(3-4)$ pp. I52-I67

Alrøe, H.F. and E. Noe (20I2) Observing environments. Constructivist Foundations 8 (I) pp. 39-5I

Alrøe, H.F. and E. Noe (20I4) Second-order science of interdisciplinary research: A polyocular framework for wicked problems. Constructivist Foundations io (I) pp. 65-95

Askegaard, M., K. Thorup-Kristensen, H.L. Pedersen et al. (2008) Muligheder og barrierer i den $ø$ kologiske planteproduktion. Pp. I87-222 in H.F. Alrøe and N. Halberg eds, Udvikling, vakst og integritet $i$ den danske økologisektor (Foulum: ICROFS)

Bruckmeier, K. and H. Tovey (2008) Knowledge in sustainable rural development: from forms of knowledge to knowledge processes. Sociologia Ruralis 48 (3) pp. 3I3-329

Collinson, M.P. (2000) A history of farming systems research (Wallingford: CABI)

Flyvbjerg, B. (2006) Five misunderstandings about case-study research. Qualitative Inquiry I2 (2) pp. 2I9-245

Fog, E. (20I3) HighCrop - billedredskab. Rapport om afprøvning af redskabet. [HighCrop picture planning tool. Report on testing.]. (Aarhus: Videncenter for Landbrug) Available online at http://orgprints.org/24450 Accessed I6 December 2014

Frankl, V.F. (I962) Man's search for meaning - an introduction to logotherapy (New York: Simon $\&$ Schuster)

Hildebrand, P.E.R..J.T. (I996) Adaptability analysis: a method for the design, analysis and interpretation of on-farm research-extension (Ames, IA: Iowa State University Press)

Hojem, T.H.M. (2012) Bridging two worlds? The troubled transfer of new environmental knowledge from science to consulting engineers. Acta Sociologica 55 (4) pp. 32I-334

Jacobson, N., D. Butterill and P. Goering (2005) Consulting as a strategy for knowledge transfer. Milbank Quarterly 83 (2) pp. 299-32I

Jasimuddin, S.M. and Z. Zhang (2009) The symbiosis mechanism for effective knowledge transfer. Journal of the Operational Research Society 60 (5) pp. 706-716

Jørgensen, L., E. Noe, G. Nielsen et al. (2008) Problems with disseminating information on disease control in wheat and barley to farmers. European Journal of Plant Pathology I2I (3) pp. 303-312 
Klerkx, L., M. Schut, C. Leeuwis et al. (20I2) Advances in knowledge brokering in the agricultural sector: towards innovation system facilitation. IDS Bulletin 43 (5) pp. 53-6o

Kloppenburg, J.R.J. (I99I) Social theory and the re/deconstruction of agricultural science: local knowledge for an alternative agriculture. Rural Sociology 56 (4) pp. 519-548

Knickel, K., G. Brunori, S. Rand et al. (2009) Towards a better conceptual framework for innovation processes in agriculture and rural development: from linear models to systemic approaches. Journal of Agricultural Education and Extension I5 (2) pp. I3I-I46

Koutsouris, A. (2012) Facilitating agricultural innovation systems: a critical realist approach. Studies in Agricultural Economics II4 (2) p. 64-70

Kvale, S. and S. Brinkmann (2009) Interviews: learning the craft of qualitative research interviewing (London: Sage)

Lamine, C. (2OII) Transition pathways towards a robust ecologization of agriculture and the need for system redesign. Cases from organic farming and ipm. Journal of Rural Studies 27 (2) pp. 209-2I9

Langvad, A.M. and E. Noe (2006) (Re-)innovating tools for decision-support in the light of farmers' various strategies. Pp. 335-339 in H. Langeveld and N. Röling eds, Changing European farming systems for a better future - new visions for rural areas (Wageningen: Wageningen Academic Publishers)

Leeuwis, C. (2004) Communication for rural innovation: rethinking agricultural extension 3rd edn (Oxford: Blackwell Science)

Leeuwis, C. and N. Aarts (20II) Rethinking communication in innovation processes: creating space for change in complex systems. Journal of Agricultural Education and Extension I7 (I) pp. $2 \mathrm{I}-36$

Levin, D.Z. (2000) Organizational learning and the transfer of: an investigation of quality improvement. Organization Science II (6) pp. 630-647

Luhmann, N. (I990) Essays on self-reference (New York: Colombia University Press)

Luhmann, N. (I995) Social systems (Stanford, CA: Stanford University Press)

McCown, R.L. (2002) Locating agricultural decision support systems in the troubled past and socio-technical complexity of 'models for management'. Agricultural Systems 74 (I) pp. II-25

Madsen, M.L. and E. Noe (20I2) Communities of practice in participatory approaches to environmental regulation. Prerequisites for implementation of environmental knowledge in agricultural context. Environmental Science \& Policy I8 pp. 25-33

Mahon, M., M. Farrell and J. McDonagh (2010) Power, positionality and the view from within: agricultural advisers' role in implementing participatory extension programmes in the republic of Ireland. Sociologia Ruralis 50 (2) pp. I04-I20

Morgan, S.L. (20II) Social learning among organic farmers and the application of the communities of practice framework. Journal of Agricultural Education and Extension I7 (I) pp. 99-II2

Newton, P.M. and L. Sackney (2005) Group knowledge and group knowledge processes in school board decision making. Canadian Journal of Education/Revue Canadienne De L'éducation 28 (3) pp. 434-457

Noe, E. and H.F. Alrøe (2003) Farm enterprises as self-organizing systems: a new transdisciplinary framework for studying farm enterprises? International Journal of Sociology of Agriculture and Food II (I) pp. 3-I4

Noe, E. and H.F. Alrøe (2005) The challenge of management of multidimensional enterprises analysed from a logo-poietic perspective. Working paper Available online at http://goo.gl/ EQ JCBp Accessed 23 November 2014

Noe, E. and H.F. Alrøe (2006) Combining Luhmann and actor-network theory to see farm enterprises as self-organizing systems. Cybernetics \& Human Knowing I3 (I) pp. 34-48

Noe, E. and H.F. Alrøe (20I2) Observing farming systems: insights from social systems theory. Pp. 387-403 in I. Darnhofer, D. Gibbon and B. Dedieu eds, Farming systems research into the 2Ist century: the new dynamic (Dordrecth: Springer) 
Noe, E. and N. Halberg (2002) Research experience with tools to involve farmers and local institutions in developing more environmentally friendly practices. Pp. I43-I6I in K. Hagedorn ed., Environmental co-operation and institutional change (Cheltenham: Edward Elgar)

Norgaard, R.B. (I994) Development betrayed: the end of progress and a coevolutionary revisioning of the future (New York: Routledge)

Olesen, J.E., M. Askegaard and I.A. Rasmussen (2000) Design of an organic farming crop-rotation experiment. Acta Agriculturae Scandinavica, Section B - Soil \& Plant Science 50 (I) pp. I3-2I

Ospina, S.M. and J. Dodge (2005) Narrative inquiry and the search for connectedness: practitioners and academics developing public administration scholarship. Public Administration Review 65 (4) pp. 409-423

Padel, S. (200I) Conversion to organic farming: a typical example of the diffusion of an innovation? Sociologia Ruralis 4I (I) pp. 40-6I

Ploeg, J.D. van der and A. Long eds (I994) Born from within: practice and perspectives of endogenous rural development (Assen: Van Gorcum)

Quaghebeur, K., J. Masschelein and H.H. Nguyen (2004) Paradox of participation: giving or taking part? Journal of Community \& Applied Social Psychology I4 (3) pp. I54-I65

Röling, N. and M.A.E. Wagemakers (I998) Facilitating sustainable agriculture. Pp. I-22 in N. Röling and M.A.E. Wagemakers eds, Facilitating sustainable agriculture - participatory learning and adaptive management in times of environmental uncertainty (Cambridge: Cambridge University Press)

Rossi, V., F. Salinari, S. Poni et al. (20I4) Addressing the implementation problem in agricultural decision support systems: the example of vite.Net@. Computers and Electronics in Agriculture 100 (0) pp. 88-99

Ruttan, V.W. (1996) What happened to technology adoption-diffusion research? Sociologia Ruralis 36 (I) pp. 5I-73

Tovey, H. (2008) Introduction: rural sustainable development in the knowledge society era. Sociologia Ruralis 48 (3) pp. I85-199

Vaarst, M., T.B. Nissen, S. Østergaard et al. (2007) Danish stable schools for experiential common learning in groups of organic dairy farmers. Journal of Dairy Science 90 (5) pp. 2543-2554

Warner, K.D. (2008) Agroecology as participatory science: emerging alternatives to technology transfer extension practice. Science, Technology Q Human Values 33 (6) pp. 754-777

\author{
Egon Noe* \\ Dept. of Agroecology \\ Aarhus University \\ 50 Blichers Alle 20 \\ Tjele 8830 \\ Denmark
}

e-mail: egon.noe@agrsci.dk

Hugo F. Alrøe

Dept. of Agroecology

Aarhus University

50 Blichers Alle 20

Tjele 8830

Denmark 
Martin H. Thorsøe Dept. of Agroecology Aarhus University 50 Blichers Alle 20

Tjele 8830 Denmark

Jørgen Eivind Olesen Dept. of Agroecology

Aarhus University 50 Blichers Alle 20 Tjele 8830 Denmark

Peter Sørensen Dept. of Agroecology Aarhus University 50 Blichers Alle 20 Tjele 8830 Denmark

Bo Melander Dept. of Agroecology Aarhus University 50 Blichers Alle 20

Tjele 8830 Denmark

Erik Fog Knowledge Centre for Agriculture Aarhus Denmark 